Original Research Article

\title{
Drug utilization pattern in an intensive care unit of a teaching hospital in South India
}

\author{
Suraj B. ${ }^{1}$, Srikanth $^{1 *}$, Somashekara S. C. ${ }^{1}$, Sandeep B. ${ }^{2}$, Tanuja ${ }^{1}$
}

${ }^{1}$ Department of Pharmacology, ESIC Medical College, Gulbarga, Karnataka, India ${ }^{2}$ Department of Pharmacology, CIMS, Chamarajanagar, Karnataka, India

Received: 30 May 2019 Accepted: 17 June 2019

\section{*Correspondence to: \\ Dr. Srikanth, \\ Email: Pharmacsrikanth@ gmail.com}

Copyright: (C) the author(s), publisher and licensee Medip Academy. This is an openaccess article distributed under the terms of the Creative Commons Attribution NonCommercial License, which permits unrestricted noncommercial use, distribution, and reproduction in any medium, provided the original work is properly cited.

\begin{abstract}
Background: Polypharmacy and inappropriate usage of antibiotics are common in an Intensive Care Unit (ICU) which may increase morbidity, mortality, antimicrobial resistance and treatment cost. Hence, drug utilization research is crucial for measuring drug consumption using DDD/100 bed-days formula proposed by the WHO that would possibly be useful while formulating a comprehensive antibiotic policy for the institution and guide for future interhospital or institutional comparisons. Therefore, in this study, we proposed to evaluate the drug utilization patterns in the ICU.

Methods: A prospective observational study was conducted for 3 months from June 2018 to August 2018, and the data were obtained from the ICU of a tertiary care hospital. The demographic data, disease data, the utilization of different classes of drugs (WHO-ATC classification) as well as individual drugs were recorded.

Results: One hundred and twelve patient's data were evaluated. About $90 \%$ patients were prescribed with antiulcer medications during their ICU stay followed by antibiotics in more than $89 \%$ patients. Azithromycin, levofloxacin, metronidazole, ofloxacin, ceftriaxone and amoxicillin/clavulanic acid were maximally utilized antibiotics with $24,16.43,14.27,13.89,12.22$ and 10.97 DDD/100 bed-days respectively.

Conclusions: Antiulcer medications were most commonly prescribed followed by antibiotics during ICU stay. Average numbers of drugs prescribed per patients were high. Regular prescription audit and modification of antibiotic policy is required to curtail the polypharmacy and inappropriate use of antibiotics.
\end{abstract}

Keywords: Antibiotics, Daily defined doses, Drug utilization, Intensive care unit

\section{INTRODUCTION}

Patients admitted to Intensive care unit (ICU) settings are administered with large number of drugs, most being seriously ill and suffering from various complications, thereby increasing the cost of drug treatment and costs of hospitalization. Antibiotics are the commonly prescribed drugs in ICU settings patients and the majority of these drugs are empirically prescribed and on physician discretion ensuing in the lack of quantitative precision of drugs usage. ${ }^{1,2}$
Though there are a number of guidelines with regards to proper drug use in ICUs, at times it may not be possible to put into practice because of patient specific disease states and preferred medication choice by physician. ${ }^{3}$

Therefore, drug utilization studies play a vital role to know the drug usage in populations and its impact on the health care system. ${ }^{4}$ World Health Organization (WHO) in 1977 defined the drug utilization study as the marketing, distribution, prescription and use of drugs in a society, with 
special importance on the resulting medical, social and economic outcomes. ${ }^{5}$

Given that various drugs are prescribed to patients admitted to ICU, making them vulnerable to medication errors and adverse drug reactions; drug utilization studies thus plays a crucial part of pharmacoepidemiology as it depicts the level, types of drugs use and determinants of drug exposure. ${ }^{6,5}$ Over all, to improve therapeutic practices in an ICU setting, the drug utilization studies have proved to be useful and inexpensive. ${ }^{7}$

Drug utilization trends needs to be addressed without delay in the ICU. Therefore, the present study was undertaken with an aim to estimate the drug utilization pattern in the ICU.

\section{METHODS}

\section{Study design}

This study was prospective, observational in nature, conducted in an ICU at ESIC Medical College and Hospital, Gulbarga, Karnataka, from June 2018 to August 2018. The study was started after obtaining approval from the Institutional Human Ethics Committee. Patients of either sex, aged 18 years or older, admitted to ICU for $>24$ $\mathrm{h}$ and willing to provide informed consent were included in the study. Patients of age lesser than 18 years and who were transferred to other specialty ICUs/wards from general ICU or discharged/death within $24 \mathrm{~h}$ of admission were excluded from the study.

Data were recorded daily on a pre-designed case report form. The following parameters were evaluated.

- $\quad$ Patient demographic profile

- Mean length of stay (LOS) in ICU

- Associated co-morbidities

- Percentage of oral/parenteral route of administration

- Number of drugs received by the patients

- Average number of drugs per patient

- Prescription frequency of class of drugs (WHO-ATC classification $)^{8}$

Utilization of commonly used drugs of different class in ICU presented as DDD/100 bed-days (WHO/DDD) ${ }^{8}$

- Formula for calculating DDD per 100 bed-days is: ${ }^{9}$

DDD/100 bed days=Number of units administered in a given period $(\mathrm{mg}) / \mathrm{DDD}(\mathrm{mg}) \times$ number of days in the period $\times$ number of beds $\times$ occupancy inde $x \times 100$

- $\quad$ Number of beds in ICU $=12$

- Occupancy index for that period in our ICU was 0.72

Data were collected in Microsoft Excel software and interpreted by applying descriptive analysis using IBM SPSS Statistics for Windows, Version 22.0. Armonk,
NY:IBM Corp. $\mathrm{P}$ value $<0.05$ was considered to be statistically significant.

\section{RESULTS}

A total of 112 patients were admitted in the ICU during the study period after taking into consideration of inclusion criteria. Seventy $(62.50 \%)$ were males and $42(37.50 \%)$ were females among 112 patients (Table 1).

Table 1: Demographic characteristics of the Study Population $(\mathrm{n}=112)$.

\begin{tabular}{|lll|}
\hline Age (years) & Number & Percentage $(\%)$ \\
\hline$\leq 35$ & 19 & 16.96 \\
\hline $36-50$ & 28 & 25 \\
\hline $51-65$ & 43 & 38.39 \\
\hline$\geq 66$ & 22 & 19.64 \\
\hline Gender & & \\
\hline Male & 70 & 62.50 \\
\hline Female & 42 & 37.50 \\
\hline
\end{tabular}

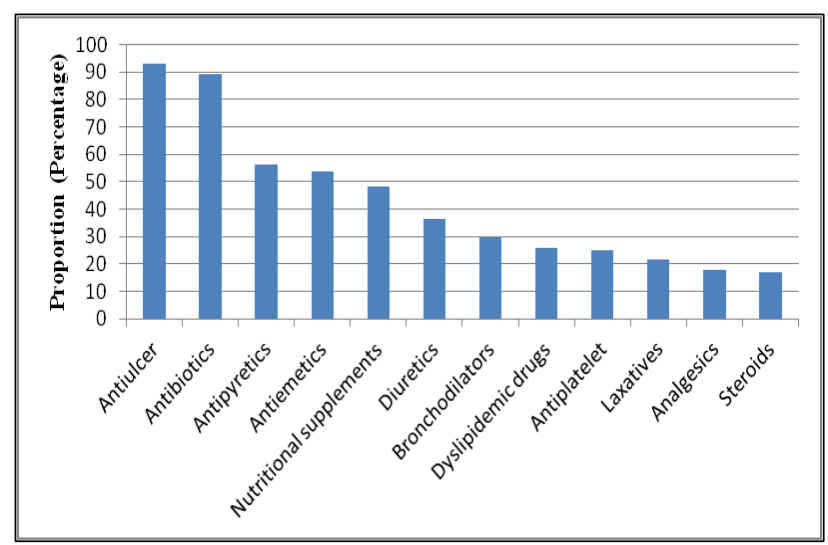

Figure 1: Percentage of patients who received various classes of drugs during a stay in the intensive care unit.

Table 2: Common antibiotic consumption presented as DDD/100 bed-days.

\begin{tabular}{|llll|}
\hline Antibiotic & ATC Code & DDD $(\mathrm{g})$ & $\begin{array}{l}\text { DDD/100 } \\
\text { bed days }\end{array}$ \\
\hline Azithomycin & J01FA10 & 0.3 & 24 \\
\hline Levofloxacin & J01MA12 & 0.5 & 16.43 \\
\hline Metronidazole & J01XD01 & 1.5 & 14.27 \\
\hline Ofloxacin & J01MA01 & 0.4 & 13.89 \\
\hline Ceftriaxone & J01DD04 & 2 & 12.22 \\
\hline $\begin{array}{l}\text { Amoxicllin/ } \\
\text { Clavulanic acid }\end{array}$ & J01CR02 & 3 & 10.97 \\
\hline Amikacin & J01GB06 & 1 & 10.21 \\
\hline Meropenem & J01DH02 & 3 & 9.93 \\
\hline $\begin{array}{l}\text { Cefoperazone/ } \\
\text { sulbactum }\end{array}$ & J01DD62 & 4 & 8.86 \\
\hline Cefotaxime & J01DD01 & 4 & 6.27 \\
\hline
\end{tabular}


The age of the patients ranged from 18 to 87 years. The mean age of all the patients was $52.9 \pm 17$. . However, it was of similar trend in males and females and found to be $53 \pm 16.2$ and $52.7 \pm 18.6$, respectively. ICU stay in days ranged from 2 to 24 days with an average of $5.32 \pm 4.26$ days. The prescribed drugs were in diverse classes; of some were of empirical, some prophylactic, whereas others were therapeutic in nature. Of 108 different drugs, 65 belong to the WHO's essential drug list. Another 3 were belonged to the WHO complementary essential drug list. Fifty seven percent of the drugs were prescribed as trade names. The number of different drugs for each patient ranged from 3 to 20. On an average, patients received 8.6 different drugs during the entire stay in ICU. Figure 1 shows the percentage of patients who used diverse classes of drugs. More than $90 \%$ of patients used antiulcer/antireflux medications, antibiotics in more than
$89 \%$ of patients, antipyretics, antiemetics and nutritional supplements were used in $30 \%$ to $60 \%$ of the patients.

Table 2 shows the details of most commonly antibiotic used and its daily defined doses. Table 3 shows common drugs prescribed in individual classes and its daily defined doses. Among antiulcer drugs, proton pump inhibitors were often used. Similarly, among antipyretics, oral paracetamol was often prescribed. Similar proportion of patients received clopidogrel and aspirin. Antiemetics were administered in more than $50 \%$ of patients. Lorazepam was the often-used sedative, followed by diazepam. Table 4 describes the number of patients prescribed with antibiotics. Nearly $37.5 \%$ of patients received 1 antibiotic, $32.14 \%$ of patients received 2 antibiotics and $11.61 \%$ received 3 antibiotics.

Table 3: Various drug classes, drug type and daily defined doses.

\begin{tabular}{|c|c|c|c|c|}
\hline Name of Drug & Proportions & ATC & DDD (g) & DDD/100 bed-day \\
\hline \multicolumn{5}{|l|}{ Antiulcer, antireflux } \\
\hline Pantoprazole & 86.60 & $\mathrm{~A} 02 \mathrm{BC} 02$ & 0.04 & 17.68 \\
\hline Pantoprazole (O) & 17.86 & $\mathrm{~A} 02 \mathrm{BC} 02$ & 0.04 & 19.16 \\
\hline \multicolumn{5}{|l|}{ Antipyretics } \\
\hline Paracetamol & 24.10 & N02BE01 & 3 & 5.68 \\
\hline Paracetamol (O) & 44.64 & N02BE01 & 3 & 3.38 \\
\hline \multicolumn{5}{|l|}{ Antiemetics } \\
\hline Ondansetron & 50.89 & A04AA01 & 0.016 & 5 \\
\hline \multicolumn{5}{|c|}{ Nutritional supplements } \\
\hline Iron Sucrose & 10.71 & B03AC & 0.1 & 16.94 \\
\hline Calcium (O) & 6.25 & A12AA04 & 3 & 2.65 \\
\hline \multicolumn{5}{|l|}{ Diuretics } \\
\hline Furosemide & 16.96 & C03CA01 & 0.04 & 10 \\
\hline Spironolactone $(\mathrm{O})$ & 7.14 & C03DA01 & 0.075 & 9.25 \\
\hline \multicolumn{5}{|l|}{ Antiplatelets } \\
\hline Clopidogrel & 16.07 & B01AC04 & 0.075 & 14.65 \\
\hline Aspirin & 13.39 & B01AC06 & & \\
\hline \multicolumn{5}{|c|}{ Analgesics and sedatives } \\
\hline Tramadol & 9.8 & N02AX02 & 0.3 & 2.87 \\
\hline Lorazepam & 7.14 & N05BA06 & 0.0025 & 7.02 \\
\hline Diclofenac & 12.25 & M01AB05 & 0.1 & 15.63 \\
\hline Diazepam & 2.67 & N05BA01 & 0.01 & 13.38 \\
\hline \multicolumn{5}{|l|}{ Steroids } \\
\hline Hydrocortisone & 8 & H02AB09 & 0.030 & 94.19 \\
\hline Prednisolone $(\mathrm{O})$ & 3.57 & H02AB06 & 0.01 & 13.89 \\
\hline \multicolumn{5}{|l|}{ Antiepileptics } \\
\hline Phenytoin & 5.36 & N03AB02 & 0.3 & 12.73 \\
\hline Valproic acid & 6.25 & N03AG01 & 1.5 & 8.49 \\
\hline Levetiracetam & 5.36 & N03AX14 & 1.5 & 9.26 \\
\hline
\end{tabular}

Daily defined doses have been expressed in grams (g). O: Oral preparations.

\section{DISCUSSION}

The demographic characteristics of the patients revealed that nearly $38.39 \%$ of patients belonged to age group of
51-65 years. Patients of more than 50 years of age constituted to $65 \%$ (Table 1). These finding correlates with the findings of study conducted by Badar VA et al, in an ICU. ${ }^{(1)}$ The mean age of all patients was around 53 years 
which was found to be similar for both sexes. This finding corroborated with previous studies which showed a similar trend of around 50 years in mean age of all patients and with negligible difference in males and females. ${ }^{9-11}$

\section{Table 4: Number of antimicrobial agents prescribed per patient.}

\begin{tabular}{|lll|}
\hline $\begin{array}{l}\text { Number of } \\
\text { antibiotics } \\
\text { prescribed }\end{array}$ & $\begin{array}{l}\text { Total number } \\
\text { of patients } \\
(\mathbf{n = 1 1 2})\end{array}$ & Percentage \\
\hline 1 & 42 & 37.5 \\
\hline 2 & 36 & 32.14 \\
\hline 3 & 13 & 11.61 \\
\hline 4 & 6 & 5.36 \\
\hline 5 & 3 & 2.68 \\
\hline
\end{tabular}

Average LOS in ICU was found to be 5.32 days in our study which correlates with the previous studies conducted in ICUs with average LOS in ICU being 5.65 and 6.22 days respectively. This difference in the average LOS could be attributed to the divergence in disease pattern among the population. ${ }^{10,11}$

The average number of drugs received by patients in our study was 8.6 drugs, and was comparable ( 8 per patient) to the study conducted in an ICU in Oman. ${ }^{12}$ However, it was less when compared to study conducted by Pandiamunian $\mathrm{j}$ et al, (10.4 \pm 2 drugs), Smythe et al, (12 \pm 7.6 drugs) and Lisha et al, (11.6 \pm 2 drugs). ${ }^{13-15}$ This difference could be attributed to smaller duration of study and difference in the illness pattern. Nevertheless, polypharmacy was still observed in majority of case records in our study.

The average number of drugs prescribed per prescription plays a key role during prescription audit. Therefore, to reduce the risk of drug interactions, hospital cost and development of bacterial resistance, it is recommended to minimize polypharmacy. ${ }^{16}$ In present study, out of total 112 patients, $104(92.86 \%)$ patients received antiulcer drugs which is high and could be prophylactic in nature to prevent ulcer due to higher burden of drugs prescribed and stress in an ICU. Hundred (89.28\%) patients received one or more antibiotic during their ICU stay which is slightly lesser than the recent Indian study conducted by Anand N et al, which could be attributed to smaller sample size and shorter duration of study period and remaining 12 $(10.71 \%)$ patients did not receive antibiotic. Antibiotic policy varies from hospital to hospital and among different departments of the same hospital. ${ }^{17}$

Patients treated in ICUs are 5 to 10 times more prone to develop nosocomial infections. ${ }^{18}$ Patient arriving in our ICU in an intubated condition was put on prophylactic antibiotics to prevent the development of nosocomial infections. However, antibiotics were stopped after 7 to 10 days if fever or any other signs of infection was not found. If any signs of infection did not resolve or reappeared beyond 14 days of antibiotic use, a newer antibiotic were added or previous ones were changed because of the suspicion of resistance. Some of the antibiotics were modified based on microbiological culture and sensitivity reports. This possibly explains increased antibiotic utilization $(89.28 \%)$ in the present study. Therefore, further studies are required to explore any specific factors responsible for this and the clinical relevance of the higher number of antibiotics used during the course of treatment in our ICU setup.

The most common antibiotics used (quantitatively) in our study were azithromycin, levofloxacin, metronidazole, ofloxacin, ceftriaxone and amoxicillin/clavulanic acid whose utilization were $24,16.43,14.27,13.89,12.22$ and 10.97 DDD/100 bed-days, respectively. On reviewing similar studies from India, most utilized antibiotics were 3rd generation cephalosporins (18.48), meropenem (16.47), metronidazole (14.65), levofloxacin (15.97), and ceftriaxone (13.42). ${ }^{2}$ This change in pattern of utilization could be attributed to change in culture sensitivity pattern and the practice of antibiotic use policy. Thus the above finding from our study highlights the significance of the antibiotic use policy, need for regular prescription audit and modification of the policy based on changes in culture sensitivity patterns. Nevertheless, by considering diverse patient's population from an ICU of tertiary care hospital, adds strength to this study. However, the drawback is that it is restricted to single centre with smaller sample size, and not considering the specific factors which could explain the higher usage of antibiotics, thereby limiting the generalizability of this study.

\section{CONCLUSION}

Antiulcer medications were most commonly prescribed followed by antibiotics during ICU stay. Average numbers of drugs prescribed per patients were high. Regular prescription audit and modification of antibiotic policy is required to curtail the polypharmacy and inappropriate use of antibiotics.

\section{ACKNOWLEDGEMENTS}

Authors would like to thank ICU staff for their kind support.

Funding: No funding sources

Conflict of interest: None declared

Ethical approval: The study was approved by the Institutional Ethics Committee

\section{REFERENCES}

1. Badar VA, Navale SB. Study of prescribing pattern of antimicrobial agents in medicine intensive care unit of a teaching hospital in Central India. J Assoc Physicians India. 2012;60:20-3.

2. Williams A, Mathai AS, Phillips AS. Antibiotic prescription patterns at admission into a tertiary level 
intensive care unit in Northern India. J Pharm Bioallied Sci. 2011;3(4):531-6

3. Bobek MB, Hogg LH, Bair N, Slomka J, Mion LC, Arroliga AC. Utilization patterns, relative costs, and length of stay following adoption of MICU sedation guidelines. Formulary. 2001;36(9):664-73.

4. Sachdeva PD, Patel BG. Drug utilization studies scope and future perspectives. Int J Pharm Biol Res. 2010;1(1):11-7.

5. The WHO Essential Medicines and Health Products Information Portal [Internet] [updated 2018 Oct 29; cited 2019 May 9]. Available at: http://apps.who.int/medicinedocs/en/d/Js4876e/2.htm 1\#Js4876e.2.1

6. Yamashita SK, Louie M, Simor AE, Rachlis A. Microbiological surveillance and parenteral antibiotic use in a critical care unit. Can $J$ Infect Dis. 2000;11(2):107-11.

7. Biswal S, Mishra P, Malhotra S, Puri GD, Pandhi P. Drug utilization pattern in the intensive care unit of a tertiary care hospital. J Clin Pharmacol. 2006;46(8):945-51.

8. WHO Collaborating Centre for Drug Statistics Methodology. Guidelines for ATC Classification and DDD Assignment; 2019:1-283. Available at: https://www.whocc.no/filearchive/publications/2019_ guidelines_web.pdf [Last accessed 2019 May 9].

9. Shankar PR, Partha P, Dubey AK, Mishra P, Deshpande VY. Intensive care unit drug utilization in a teaching Hospital in Nepal. Kathmandu Univ Med J. 2005;3(2):130-7.

10. Amit GS. Drug use evaluation study in a tertiary care corporate hospital with special reference to use of antibiotics in ICU department. Int J Adv Pharm Biol Chem. 2013;2(1):179-89.

11. John LJ, Devi P, John J, Guido S. Drug utilization study of antimicrobial agents in medical intensive care unit of a tertuart care hospital. Asian J Pharm Clin Res. 2011;4(2):81-4.
12. Al-Zakwani I, Al-Thuhli M, Al-Hashim A, Al Balushi KA. Drug utilization pattern in an intensive care unit at a tertiary care teaching hospital in Oman. Asian J Pharm Clin Res. 2017;10(2):194-7.

13. Pandiamunian J, Somasundaram G. A study on prescribing pattern of anti-microbial agents in the medical intensive care unit of a tertiary care teaching hospital in Puducherry union territory, South India. Int J Pharm Pharm Sci. 2014;6(3):235-8.

14. Smythe MA, Melendy S, Jahns B, Dmuchowski. An exploratory analysis of medication utilization in a medical intensive care unit. Crit Care Med. 1993;21(9):1319-23.

15. Lisha JJ, Padmini D, Jenny J, Shoba G. Drug Utilization Study of Antimicrobial agents in Medical intensive care unit of a tertiary care hospital. Asian J Pharm Clin Res. 2011;4(2):81-4.

16. Stratton CW, Ratner H, Johnston PE, Schaffner W. Focused microbiologic surveillance by specific hospital unit: Practical application and clinical utility. Clin Ther. 1993;15 (Suppl A):12-20.

17. Anand N, Nagendra Nayak IM, Advaitha MV, Thaikattil NJ, Kantanavar KA, Anand S. Antimicrobial agents' utilization and cost pattern in an Intensive Care Unit of a Teaching Hospital in South India. Indian J Crit Care Med. 2016;20(5):274-9.

18. Weber DJ, Raasch R, Rutala WA. Nosocomial infections in the ICU: the growing importance of antibiotic-resistant pathogens. Chest. 1999;115(3 Suppl):34-41.

Cite this article as: Suraj B, Srikanth, Somashekara SC, Sandeep B, Tanuja. Drug utilization pattern in an intensive care unit of a teaching hospital in South India. Int J Basic Clin Pharmacol 2019;8:1527-31. 